\title{
Sepsis and Development Impede Muscle Protein Synthesis in Neonatal Pigs by Different Ribosomal Mechanisms
}

\author{
RENÁN A. ORELLANA, FIONA A. WILSON, MARÍA C. GAZZANEO, AGUS SURYAWAN, TERESA A. DAVIS, \\ AND HANH V. NGUYEN
}

Department of Pediatrics, Baylor College of Medicine, Houston, Texas 77030

\begin{abstract}
In muscle, sepsis reduces protein synthesis (MPS) by restraining translation in neonates and adults. Even though protein accretion decreases with development as neonatal MPS rapidly declines by maturation, the changes imposed by development on the sepsis-associated decrease in MPS have not been described. Pigs at 7 and $26 \mathrm{~d}$ of age were infused for $8 \mathrm{~h}$ with lipopolysaccharide (LPS, endotoxin, 0 and $\left.10 \mu \mathrm{g} \cdot \mathrm{kg}^{-1} \cdot \mathrm{h}^{-1}\right)$. Fractional MPS rates and translation eukaryotic initiation factor (eIF) activation in muscle were examined ( $n=5-7$ /group). The LPS-induced decrease in MPS was associated with reduced ribosomal and translational efficiency, whereas the age-induced decrease in MPS occurred by decreasing ribosome number. Abundances of mammalian target of rapamycin (mTOR) and S6 decreased, and that of the repressor eIF4E $\cdot 4 \mathrm{E}$ binding protein 1 (4EBP1) association increased in 26-d-old pigscompared with 7-d-old pigs. LPS decreased the abundance of the active eIF4E - eIF4G association and the phosphorylation of eIF4G across ages, whereas the abundance of eIF4G declined and eIF2 $\alpha$ phosphorylation increased with age. Therefore, when lacking anabolic stimulation, the decrease in MPS induced by LPS is associated with reduced ribosomal efficiency and decreased eIF4E - eIF4G assembly, whereas that induced by development involves reduced ribosomal number, translation factor abundance, and increased eIF2 $\alpha$ phosphorylation. (Pediatr Res 69: 473-478, 2011)
\end{abstract}

$S^{\text {cos }}$ epsis is the systemic response to an infectious insult (1) and a major cause of critical illness, morbidity, and mortality in pediatric patients (2), although the incidence of sepsis is about 10 times higher in infants than older children (3). Despite physiologic changes that occur with maturation, the sepsis-induced failure of the mechanisms that regulate muscle mass during critical illness have been studied only in adult and mature organisms $(4,5)$. Features of the sepsis syndrome include mobilization of muscle protein to supply nitrogen to sustain the systemic inflammatory response $(6,7)$. Experimental sepsis in mature rats decreases muscle protein

Received August 16, 2010; accepted December 29, 2010.

Correspondence: Renán A. Orellana, M.D., USDA/ARS Children's Nutrition Research Center, 1100 Bates Street, Room 9057, Houston, TX 77030; e-mail: orellana@bcm.edu

Supported by NIH awards K08 AR-51563 [R.A.O.] and AR-44474 [T.A.D.], and the US Department of Agriculture, Agricultural Research Service under Cooperative Agreement number 58-6250-6-001 [T.A.D.].

The contents of this publication do not reflect the views or policies of the US Department of Agriculture, nor does mention of trade names, commercial products, or organizations imply endorsement by the US Government. synthesis (MPS) rates by depressing translation of mRNA into protein $(8,9)$. However, the sepsis-induced decrease in MPS in neonatal pigs is less profound than that described in adult rats $(8,9)$, suggesting that different anabolic mechanisms regulate protein deposition in skeletal muscle during sepsis as the animal matures.

Enhanced MPS in neonatal pigs occurs because of increased sensitivity to insulin and amino acid stimulation, aimed to sustain protein deposition and rapid growth after feeding (10), and is driven by high rates of mRNA translation through activation of eukaryotic translation initiation factors (eIF) (11). The enhanced translational process in the neonatal period declines significantly as the animal develops, as a consequence of decreased activation of the translational machinery and reduction of the abundance of the signaling proteins that regulate translation $(12,13)$. Because sepsis impairs translation regulation in mature muscle $(4,14)$, modifications in the sepsis-induced decrease in translation activation are likely to arise as animals grow from the immediate postnatal period and decrease their high rates of eIF activation.

Translation of mRNA into protein occurs by activation of a signaling pathway involving activation of mammalian target of rapamycin (mTOR; Fig. 1) (15), which induces the phosphorylation of 4E-binding protein-1 (4EBP1). Unphosphorylated 4EBP1 is bound to eIF4E forming an inactive complex (15). Phosphorylation of 4EBP1 releases eIF4E and allows eIF4E to bind to the phosphorylated form of eIF4G, which stimulates mRNA binding to the 43S ribosomal complex. Activation of mTOR has been associated with the phosphorylation of the ribosomal protein S6 $(13,16)$. Concurrently, eIF2B stimulate binding of the initiator methionyl-tRNA (met-tRNA $\mathrm{i}_{\mathrm{i}}$ ) and a molecule of GTP to the 40S ribosomal subunit and of mRNA to the $43 \mathrm{~S}$ preinitiation complex, enhancing translation $(13,15)$. Inhibition of eIF2B, and of translation, occurs when eIF2 is phosphorylated on its $\alpha$-subunit (17). After translation initiation, dephosphorylation of the

\footnotetext{
Abbreviations: 4EBP1, 4E binding protein 1; AU, arbitrary units; eIF, eukaryotic initiation factor; eEF2, eukaryotic elongation factor 2; GLM, general linear model ANOVA; LD, longissimus dorsi muscle; LPS, lipopolysaccharide; MPS, muscle protein synthesis rates; mTOR, mammalian target of rapamycin
} 


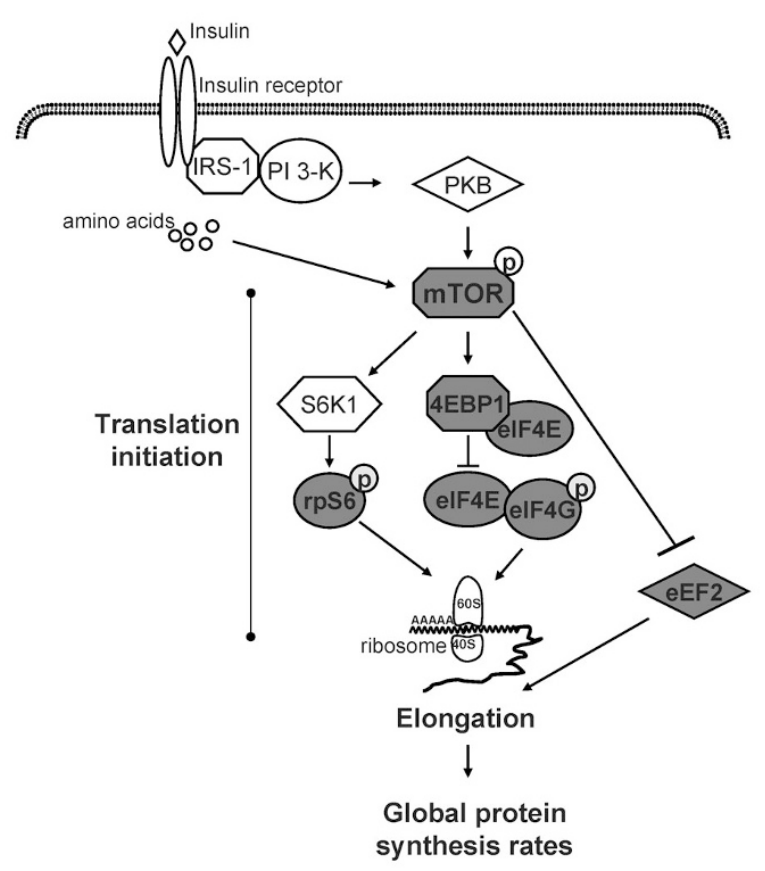

Figure 1. Insulin and amino acid signaling pathways leading to mRNA translation. IRS-1, insulin receptor substrate 1; PI3-K, phosphatidylinositol 3-kinase; PKB, protein kinase B.

eukaryotic elongation factor 2 (eEF2) enhances elongation of the peptide chain (13).

We hypothesize that the translational mechanisms that control the sepsis-induced reduction in MPS in the neonatal pig differ to those induced by development. We infused fasting 7and 26-d-old pigs with Escherichia coli (E. coli) endotoxin (lipopolysaccharide, LPS) and measured fractional MPS and examined translation signaling proteins in longissimus dorsi (LD). The results show that the decrease in MPS induced by LPS is associated with reduced ribosomal efficiency and decreased eIF4E $\cdot \mathrm{eIF} 4 \mathrm{G}$ assembly, whereas that induced by development involves reduced ribosomal number, translation factor abundance, and increased eIF $2 \alpha$ phosphorylation.

\section{MATERIALS AND METHODS}

Animals. Four pregnant crossbred sows (Landrace $\times$ Yorkshire $\times$ Hampshire $\times$ Duroc) were obtained from the Agriculture Headquarters of the Texas Department of Criminal Justice (Huntsville, TX), housed in environmentally controlled lactation crates, and provided with water ad libitum and commercial diet 2 wk before farrowing (5084; PMI Feeds, Richmond, IN). Twentysix neonatal piglets resided and suckled from the sows until studied at 6-7 d of age $(n=12,2.5 \pm 0.2 \mathrm{~kg}$ body weight $)$ and at $26 \mathrm{~d}$ of age $(n=14,7.8 \pm$ $0.8 \mathrm{~kg}$ body weight). Three days before the experiment, piglets were anesthetized for jugular vein and carotid artery sterile catheter insertion and returned to the sows. The protocol was approved by the Animal Care and Use Committee of Baylor College of Medicine and was conducted in accordance with the National Research Council's Guide for the Care and Use of Laboratory Animals.

Experimental design. Pigs were randomly assigned to control (7-d-old, $n=5$; 26-d-old, $n=7$ ) or LPS (7-d-old, $n=7 ; 26$-d-old, $n=7$ ) treatment groups. After fasting 14-16 h, pigs were placed in a sling restraint system, and concentrations of whole blood glucose and plasma insulin were obtained. The LPS group received a continuous infusion $\left(10 \mu \mathrm{g} \cdot \mathrm{kg}^{-1} \cdot \mathrm{h}^{-1}\right)$ of LPS (lyophilized E. coli Serotype 0111-B4; Sigma Chemical Co., St. Louis, MO) for $8 \mathrm{~h}$, whereas the control group received an equal volume of sterile normal saline solution. Heparinized blood samples were obtained at 1-h intervals to determine whole blood glucose concentrations by automated glucose oxidase reaction (YSI 2300 STAT Plus; Yellow Springs Instruments, Yellow Springs, $\mathrm{OH})$. Plasma was aliquoted and stored at $-70^{\circ} \mathrm{C}$ until insulin concentrations were measured by a porcine insulin RIA kit (Linco, St. Charles, MO). All animals were killed $8 \mathrm{~h}$ after the LPS infusion began with an i.v. dose of pentobarbital sodium $(50 \mathrm{mg} / \mathrm{kg}$ body weight).

Measuring protein synthesis in vivo. Fractional MPS was measured in vivo by a tracer flooding dose technique using ${ }^{3} \mathrm{H}$-phenylalanine (Phe) (18). After $8 \mathrm{~h}$ of LPS treatment, LD samples were rapidly obtained, frozen in liquid nitrogen, and stored at $-70^{\circ} \mathrm{C}$ until homogenized and processed for determination of fractional protein synthesis rates as previously described $(9,18)$.

Calculations. The fractional MPS, the percentage of protein mass synthesized in a day $(\% / \mathrm{d})$, was calculated as follows: $\left[\left(S_{\mathrm{B}} / S_{\mathrm{A}}\right) \times(1440 / t)\right] \times 100$, where $S_{\mathrm{B}}\left(\mathrm{dpm} \cdot \mathrm{nmol}^{-1}\right)$ is the specific radioactivity of the protein-bound tracer, $S_{\mathrm{A}}\left(\mathrm{dpm} \cdot \mathrm{nmol}^{-1}\right)$ is the mean specific radioactivity of the nonproteinbound tracer obtained during the labeling period (determined from the sample amount at the time of tissue collection and corrected by linear regression of the change in blood-specific radioactivity against time), $t$ is the time of labeling in minutes, and 1440 is the minutes-to-day conversion. The specific radioactivity of the nonprotein-bound tracer, the tissue-free Phe, following a flooding dose, is in equilibrium with the aminoacyl-tRNA-specific radioactivity, as previously described (18); therefore, the tissue-free Phe reflects the specific radioactivity of the tissue precursor pool. Because most of the RNA in tissues is ribosomal RNA, the RNA-to-protein ratio (mg RNA/g protein) was used to estimate protein synthetic capacity $(\mathrm{Cs})$, an indicator of ribosome number (19). Therefore, the total protein synthesized per total RNA (g protein $\cdot \mathrm{d}^{-1} \cdot \mathrm{g} \mathrm{RNA}^{-1}$ ) is indicative of the protein synthetic efficiency (19).

Protein immunoblot analysis. Muscle homogenates were separated on PAGE. Samples were run at the same time in triple-wide gels (C.B.S. Scientific C., Del Mar, CA) for each assay to eliminate interassay variation $(11,12,20)$. Proteins were electrophoretically transferred to polyvinylidene difluoride transfer membranes (Bio-Rad, Hercules, CA), which were incubated with the correct primary antibodies, washed, and exposed to a proper secondary antibody as previously described $(12,20)$. Immunoblots with antiphospho-specific antibodies were stripped in stripping buffer (Pierce Biotechnology, Rockford, IL) and reprobed with the corresponding nonphosphospecific antibodies for normalization, so the phosphorylated forms of the signaling proteins were normalized to its abundance, i.e. the total content of the respective protein. Blots were developed using an enhanced chemiluminescence kit (Amersham Life Sciences, Arlington Heights, IL), visualized, and analyzed using a ChemiDoc-It Imaging System (UVP, Upland, CA). The antibodies used in the immunoblotting process were mTOR (total and $\mathrm{Ser}^{2448}$; Cell Signaling), S6 (total and Thr ${ }^{389}$; Cell Signaling), 4EBP1 (total; Bethyl Laboratories, Montgomery, TX), eIF4G (total and Ser ${ }^{1180}$; Cell Signaling), eEF2 (total and $\mathrm{Thr}^{56}$; Cell Signaling), and eIF2 $\alpha$ (total and Ser ${ }^{51}$; Cell Signaling) $(12,20)$.

Quantification of eIF4E $\cdot$ eIF4G and eIF4E 4 EBP1 association. The eIF4E $\cdot$ eIF4G and eIF4E $\cdot 4 \mathrm{EBP} 1$ complexes were immunoprecipitated using an anti-eIF4E MAb (obtained from aliquots of fresh tissue homogenates and donated by Dr. Leonard Jefferson, Penn State University College of Medicine, Hershey, PA). Muscle homogenates were processed as previously described $(12,20)$ and immediately subjected to protein immunoblot analysis using rabbit anti-eIF4G or 4EBP1 (Bethyl Laboratories) antibodies. Amounts of eIF4G or 4EBP1 were corrected by the eIF4E recovered from the immunoprecipitate $(12,20)$.

Statistical analyses. Analysis of variance (ANOVA; general linear model (GLM); Tukey between-group analyses) was used to assess the interaction between LPS and maturation on MPS and translation factor activation and abundance (Minitab Inc. for Windows). Treatment was the grouping factor for different parameters. If effect was found by GLM, the difference among groups was determined by one-way ANOVA. Results are presented as means \pm SE. Probability values of $<0.05$ were considered statistically significant.

\section{RESULTS}

Metabolic responses. LPS induced fever regardless of age $(p<0.05$; Table 1). Tachycardia was present in the LPS animals and was greater in the 7-d-old pigs $(p<0.05$; Table 1). Blood glucose decreased in response to LPS in both 7- and 26-d-old pigs $(p<0.05$; Table 1). Circulating insulin was slightly higher in 26-d-old animals, but remained in the physiologic fasting range in all groups $(p<0.05$; Table 1$)$. LPS 
Table 1. Temperature, heart rate, and blood glucose and plasma insulin concentrations in 7- and 26-d-old pigs infused with LPS for $8 h$

\begin{tabular}{|c|c|c|c|c|}
\hline & \multicolumn{2}{|c|}{ 7-d-old } & \multicolumn{2}{|c|}{ 26-d-old } \\
\hline & Control & LPS & Control & LPS \\
\hline \multicolumn{5}{|l|}{$\begin{array}{c}\text { Temperature } \\
\left({ }^{\circ} \mathrm{F}\right)\end{array}$} \\
\hline Baseline & $101.8 \pm 0.6$ & $102.6 \pm 0.2$ & $102.9 \pm 0.5$ & $102.6 \pm 0.5$ \\
\hline Treatment & $101.5 \pm 0.5$ & $105.2 \pm 0.4^{*}$ & $102.4 \pm 0.4$ & $104.4 \pm 0.6^{*}$ \\
\hline \multicolumn{5}{|l|}{$\begin{array}{l}\text { Heart rate } \\
\qquad(\mathrm{bpm})\end{array}$} \\
\hline Baseline & $172 \pm 5$ & $174 \pm 2$ & $145 \pm 6$ & $150 \pm 4 \dagger$ \\
\hline Treatment & $168 \pm 7$ & $236 \pm 6^{*}$ & $152 \pm 6$ & $195 \pm 8 * \dagger+$ \\
\hline \multicolumn{5}{|l|}{$\begin{array}{l}\text { Glucose } \\
\text { (mg/dL) }\end{array}$} \\
\hline Baseline & $82 \pm 5$ & $83 \pm 6$ & $83 \pm 4$ & $93 \pm 4$ \\
\hline $\begin{array}{l}\text { Treatment } \\
\text { Insulin } \\
\qquad(\mathrm{mU} / \mathrm{mL})\end{array}$ & $79 \pm 4$ & $66 \pm 4^{*}$ & $88 \pm 3$ & $68 \pm 7 *$ \\
\hline Baseline & $1.8 \pm 0.5$ & $1.5 \pm 1.0$ & $3.1 \pm 0.7$ & $2.4 \pm 0.4$ \\
\hline Treatment & $1.6 \pm 0.3$ & $1.0 \pm 0.1$ & $4.2 \pm 1.1 \dagger$ & $9.5 \pm 1.9^{*+\dagger}$ \\
\hline
\end{tabular}

Values are means \pm SE; $n=5-7 /$ treatment/age. Treatment: LPS or normal saline infusion for $8 \mathrm{~h}$.

* Significantly different between control and LPS.

$\dagger$ Significantly different between 7-d-old vs 26-d-old.

\$ Interaction effect between age and LPS (GLM ANOVA and comparisons between two groups by one-way ANOVA, $p<0.05$ ).

bpm, beats per minute.

induced an elevation of circulating insulin in 26-d-old pigs only $(p<0.05$; Table 1$)$.

Muscle protein synthesis. After $14 \mathrm{~h}$ of a fasting period to avoid postabsorptive nutrient and hormonal anabolic stimulation, 26-d-old pigs had lower MPS than 7-d-old pigs in both control $(-51 \% ; p<0.05)$ and LPS-infused animals $(-55 \%$; $p<0.05$; Fig. 2A). LPS reduced MPS in both 7-d-old pigs $(-20 \% ; p<0.05)$ and 26-d-old pigs $(-27 \% ; p<0.05$; Fig. $2 A)$. LPS reduced the ribosomal protein synthetic efficiency in both age groups (7-d-old by $-25 \%$, and 26 -d-old by $-32 \%$; $p<0.05$; Fig. 2B). In contrast to the LPS effect, the protein synthetic capacity, an estimate of the ribosome number in muscle, declined with age (controls by $-53 \%$, LPS by $-58 \%$; $p<0.05$ ), but it was not affected by LPS treatment (Fig. $2 C$ ).

Translation signaling proteins in skeletal muscle. The phosphorylation state of signaling proteins was measured after
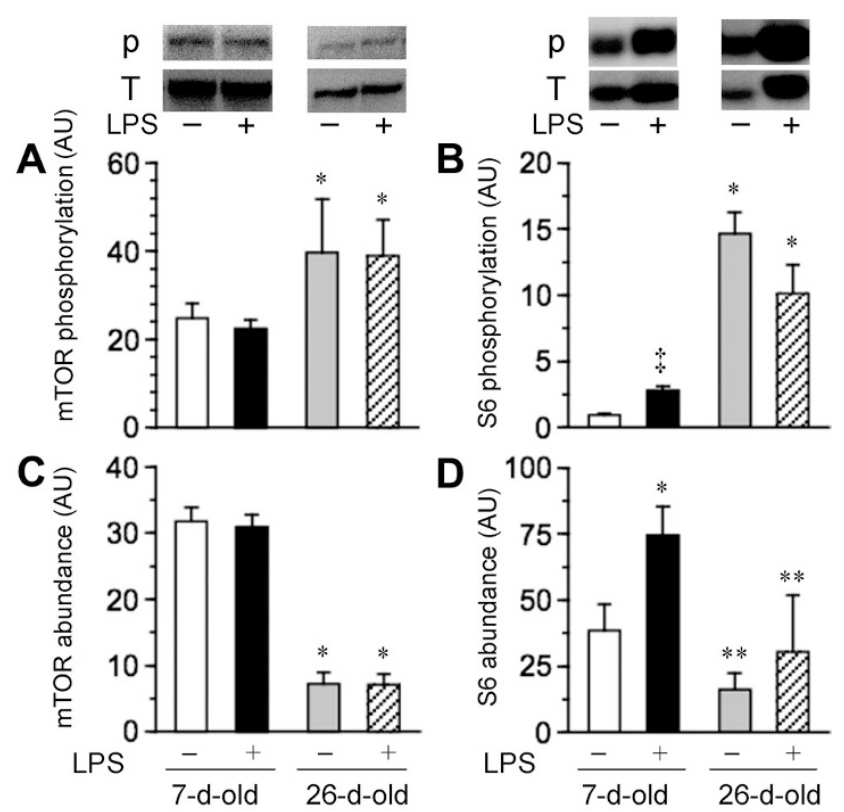

Figure 3. mTOR and $\mathrm{S} 6$ phosphorylation $(A$ and $B$, respectively $[\mathrm{p} / \mathrm{T}])$ and abundances ( $C$ and $D$, respectively, [T]) in LD of 7- and 26-d-old LPS-infused pigs. Amounts of the phosphorylated forms [p] were normalized to their abundances $[\mathrm{T}]$. Values are means $\pm \mathrm{SE} ; n=5-7 /$ treatment/age. Interaction among groups tested by GLM and comparisons between two groups by one-way ANOVA. *, $\ddagger$, and $* *: p<0.05$. AU, arbitrary units.

14-16 $\mathrm{h}$ of fasting, thus lacking the circulating insulin or amino acid stimulation that occurs postprandially. Consequently, changes in those signaling proteins should be considered in the context of nonstimulated, baseline fasting protein synthesis rates. mTOR abundance decreased with age $(p<$ 0.05 ; Fig. $3 C)$, but its relative phosphorylation $(\mathrm{p} / \mathrm{T})$ was higher in 26-d-old pigs when compared with 7-d-old pigs ( $p<$ 0.05 ; Fig. $3 A$ ), likely because of higher insulin levels in the older animals (Table 1). mTOR phosphorylation was not affected by LPS in both age groups $(p<0.05$; Fig. $3 A)$. Therefore, LPS restrained the expected insulin-associated increase in mTOR phosphorylation in 26-d-old pigs-but not in the 7-d-old pigs- because older animals had increased circulating insulin in response to LPS. S6 abundance was lesser in 26-d-old pigs-compared with 7-d-old pigs-and greater in LPS-infused 7-d-old pigs ( $p<0.05$; Fig. 3D). S6 phosphor-
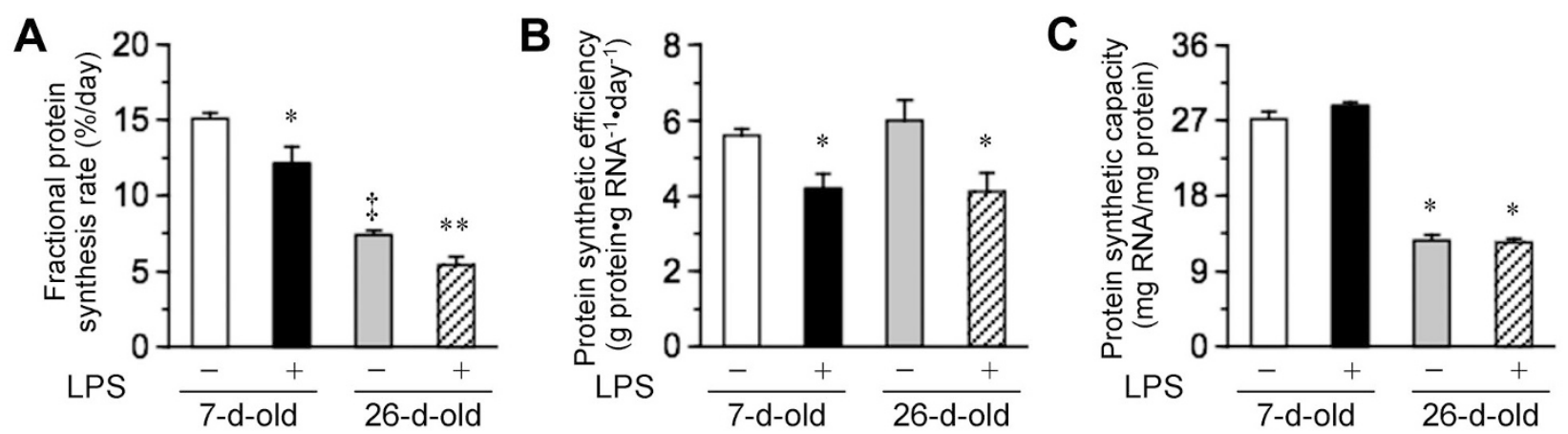

Figure 2. Fractional protein synthesis rates $(A)$, protein synthetic capacities $(B)$, and protein synthetic efficiencies $(C)$ in LD of 7-and 26-d-old pigs infused with LPS for $8 \mathrm{~h}$. Values are means $\pm \mathrm{SE} ; n=5-7 /$ treatment/age. Interaction among groups tested by GLM and comparisons between two groups by one-way ANOVA. $*$, $\neq$, and $* *$ : values with different superscript differ $(p<0.05)$. 
ylation was higher in 26-d-old pigs-when compared with 7 -d-old pigs $(p<0.05$; Fig. $3 B)$-possibly as a consequence of higher insulin concentrations in the 26-d-old animals. LPS increased S6 phosphorylation in 7- but not in 26-d-old pigs, thus LPS restrained the expected insulin-induced S6 phosphorylation in 26-d-olds, which had higher insulin concentrations than 7-d-old pigs. By GLM ANOVA, mTOR and S6 abundance were influenced by age, not affected by LPS, and thus, LPS and maturation did not interact.

The abundance of the inactive eIF4E - 4EBP1 association was greater in 26- than in 7-d-old pigs, and it was not affected by LPS, even in the presence of higher insulin concentrations in the LPS-infused 26-d-old pigs ( $p<0.05$; Fig. $4 A$ ). In contrast, LPS profoundly decreased the abundance of the active eIF4E - eIF4G association and the phosphorylation of eIF4G across ages, whereas the abundance of eIF4G declined with age ( $p<0.05$; Figs. $4 B-D$, respectively). By GLM ANOVA, eIF4E $\cdot$ eIF4G association and the phosphorylation of eIF4G were influenced by LPS, not affected by age, and thus, LPS and maturation did not interact.

The abundance of eIF $2 \alpha$ declined with age and increased in response to LPS in 7-d-old pigs only ( $p<0.05$; Fig. $5 C$ ). eIF $2 \alpha$ phosphorylation, a repressor of protein synthesis (17), was greater in 26-d-old pigs compared with 7-d-old pigs and it was not affected by LPS treatment $(p<0.05$; Fig. $5 A)$. The abundance of eEF2 was not different across ages, but its relative phosphorylation was greater in the 26-d-old pigs, suggesting a decreased elongation phase of translation in older

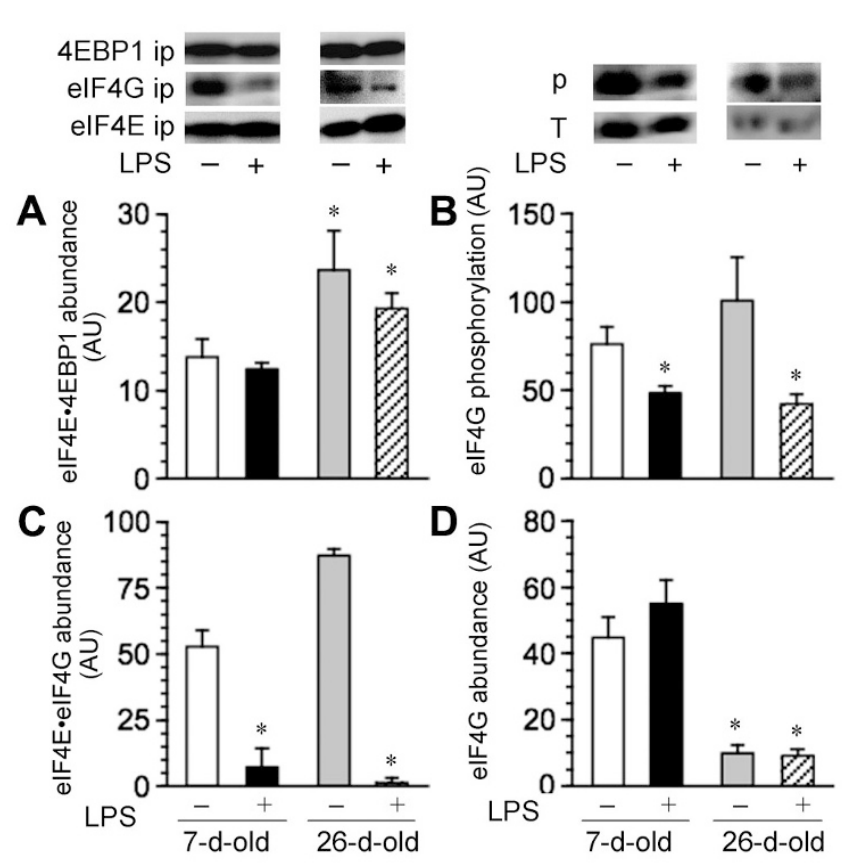

Figure 4. Abundances of the repressor eIF4E - 4EBP1 complex $(A)$, the active eIF4E $\cdot$ eIF4G complex $(C)$, and eIF4G phosphorylation $(B,[\mathrm{p} / \mathrm{T}])$, and abundance $(D,[\mathrm{~T}])$ in LD of 7 - and 26-d-old pigs infused with LPS. eIF4E - 4EBP1 and eIF4E $\cdot$ eIF4G complexes were recovered by immunoprecipitation [ip]. Amounts of the phosphorylated forms [p] were normalized to their abundances $[\mathrm{T}]$. Values are means $\pm \mathrm{SE} ; n=5-7 /$ treatment/age. Interaction among groups tested by ANOVA, GLM, and comparisons between two groups by one-way ANOVA. *: $p<0.05$. AU, arbitrary units.
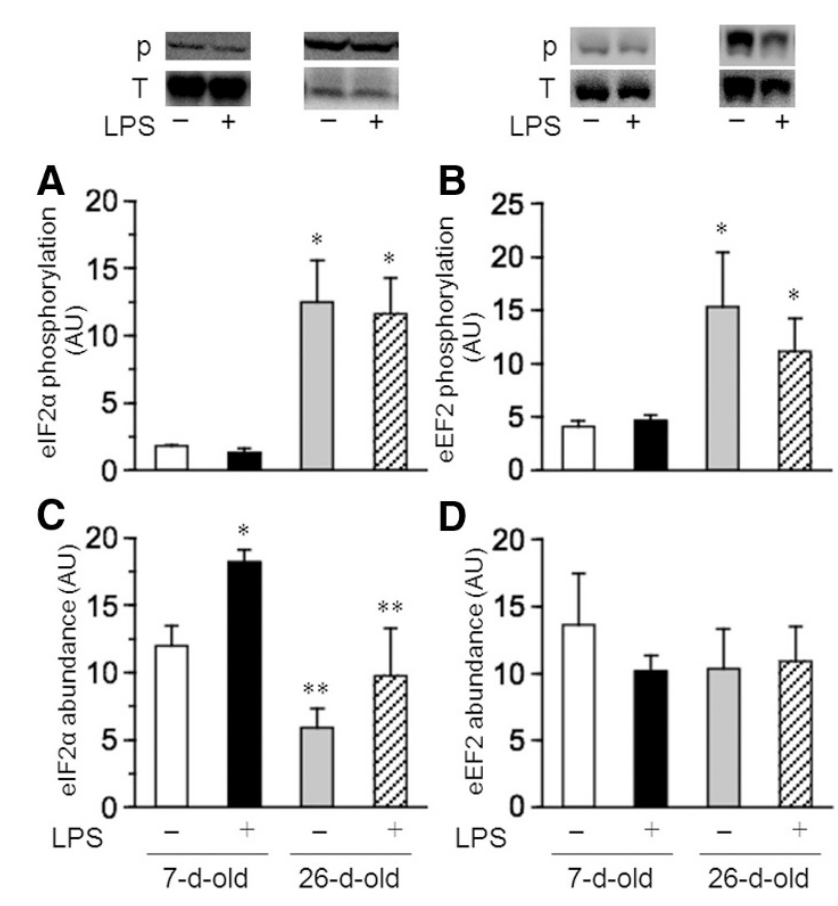

Figure 5. eIF $2 \alpha$ and eEF2 phosphorylation ( $A$ and $B$, respectively, $[\mathrm{p} / \mathrm{T}]$ ) and abundances ( $C$ and $D$, respectively, $[\mathrm{T}]$ ) in LD of 7- and 26-d-old pigs infused with LPS. Amounts of the phosphorylated forms [p] were normalized to their abundances $[\mathrm{T}]$. Values are means $\pm \mathrm{SE} ; n=5-7 /$ treatment/age. Interaction among groups tested by ANOVA, GLM, and comparisons between two groups by one-way ANOVA. * and **: $p<0.05$. AU, arbitrary units.

pigs. eEF2 phosphorylation and abundance were not affected by LPS treatment $(p<0.05$; Figs. $5 B$ and $D)$.

\section{DISCUSSION}

The molecular mechanisms that regulate MPS during sepsis have been studied mostly in mature organisms (4), and there is a gap of knowledge about how development influences the sepsis-induced reduction of MPS during the neonatal period, when MPS is uniquely elevated to sustain rapid growth (21). Because this anabolic drive decreases as the animal matures (22), it is reasonable to expect modifications in the translational machinery during sepsis as neonates develop $(4,9,23)$. The results of this study show that different ribosomal mechanisms control the decrease in MPS when it is induced by either sepsis or development.

Metabolic derangements in response to LPS in 7- and 26-d-old pigs. Consistent with previous studies, LPS induced fever and tachycardia in both age groups, but the LPS-induced tachycardia was exaggerated in the 7-d-old pigs (9). Although insulin concentrations after fasting were higher in 26-d-old control pigs, they remained within the fasting range (24). Similar to developmental rat models of endotoxemic sepsis (25), LPS induced elevation of insulin levels, likely from increased pancreatic insulin secretion, in which the magnitude of this response has been reported to differ within different stages of development (26). Because LPS raised insulin concentrations in older pigs only, and glucose concentrations decreased in both age groups in response to LPS, the native 
insulinemic response (i.e. in the absence of postabsorptive stimulation) to LPS-induced sepsis in neonates seems less robust and more sensitive than that in more mature animals.

The decrease in MPS rates induced by LPS is associated with reduced ribosomal efficiency, whereas that induced by development involves a reduction in ribosomal number. LPS reduces MPS of neonatal pigs in the presence of anabolic stimulation as a result of decreased ribosomal efficiency to translate RNA into protein (19), secondary to impaired ribosomal subunit assemblage $(4,8)$, but this reduction is less profound than that reported in adult rodents $(-11$ versus $-30 \%$ ). By fasting neonatal pigs in this study, we found that the decline in baseline MPS in conditions lacking anabolic stimulation was proportionally similar in 7- and 26-d-old pigs infused with LPS ( $-20 \%$ versus $-27 \%$, respectively). Moreover, the LPS-induced reduction in MPS in 26-d-old pigs occurred despite higher insulin concentrations, suggesting a blunted response of MPS to insulin stimulation during sepsis in older animals when compared with neonates. In the neonatal pig, insulin has been shown to stimulate MPS (10), decreasing the intensity of the stimulation as development occurs $(27,28)$, and to augment MPS in the presence of LPS (24). These data suggest that, during sepsis, the decrease in MPS in the neonate is not affected by ontogeny, but that decreased responsiveness of MPS to insulin as the neonate reaches maturity renders adult animals at risk for more profound muscle catabolism as their anabolic response is diminished.

The LPS-associated reduction in MPS in both ages was coupled to a proportional decrease in protein synthetic efficiency, without an effect on the ribosomal number. In contrast, 26-d-old pigs have decreased ribosomal apparatus capability to translate mRNA, because the ribosomal number was smaller than in 7-d-olds (28). Although the decrease in protein synthetic efficiency induced by LPS was proportionally similar in 7- and 26-d-old pigs, smaller ribosomal number in older animals may translate into less absolute protein synthesized when their efficiency is impaired by sepsis, further limiting the MPS response to insulin stimulation in adults when compared with neonates (29-31).

The LPS-induced decrease in translation activation by decreasing eIF4G eIF4E assembly lacks ontogenic modifications. In our study, the reduction in MPS and ribosomal efficiency induced by LPS from basal, nonstimulated conditions was coupled to a reduction of the abundance of the active eIF4E - eIF4G complex and a decrease in eIF4G phosphorylation in both 7- and 26-d-old pigs. Because eIF4E abundance did not change in our study (data not shown), this suggests that decreased eIF4G phosphorylation may be a key translational step altered by LPS in the sepsis-induced translation initiation inhibition. The mechanism for the repression of this translational step remains unexplained (32), and possibilities may include energy failure or cleavage of initiation factors (33). In contrast, the age-induced decrease in basal MPS occurs by decreasing eIF abundance, consistent with a reduced number of ribosomes in muscle of 26-d-old pigs. We found that the abundance of proteins that regulate translation initiation, such as mTOR, S6, and eIF4G declined as the animal matured, and the abundance of the inactive
eIF4E - 4EBP1 complex, a translation initiation repressor, increased in 26- compared with 7-d-old pigs. Although S6 phosphorylation increased in 7-d-old animals in response to LPS, our statistical analysis show that only age affected S6 phosphorylation. Currently, there is an unclear role and regulation of rpS6. Causal relationship between rpS6 phosphorylation and efficiency of protein synthesis is not clear, and some evidence suggests that protein synthesis may be downregulated by rpS6 phosphorylation (16). eIF2 $\alpha$ phosphorylation represses translation initiation $(4,17)$ and was greater in 26-d-old pigs compared with 7-d-old pigs, but it was not affected by LPS treatment. Because insulin enhances translation initiation, and the translational events in our study occurred despite elevated insulin levels in the 26-d-old LPStreated pigs, the results show lack of insulin stimulation on the LPS-induced defective eIF4E - eIF4G assembly in more mature animals when compared with neonates (24).

We found decreased activation of the elongation phase of translation in the older pigs, rather than changes on its abundance, and lack of effect of LPS on eEF2. In neonatal pigs challenged with LPS, we have shown that insulin decreases the phosphorylation of eEF2, therefore stimulating the elongation phase of translation (34). In those studies, insulin concentrations were 3 -fold of those in this study, involved controlled insulin and substrate concentrations, and did not include pigs beyond the neonatal period. Further studies at higher insulin concentrations will be required to evaluate the effect of LPS on the stimulation of the elongation phase of translation by insulin as animals grow from the neonatal period.

Perspectives. We have demonstrated that, in conditions lacking anabolic stimulation, such as fasting, the LPS-induced repression of MPS is associated with reduced ribosomal efficiency and decreased eIF4E - eIF4G assembly, whereas that induced by development involves reduced ribosomal number, translation factor abundance, and increased eIF2 $\alpha$ phosphorylation. Moreover, the LPS-induced decrease in translation activation by decreasing eIF4G $\cdot$ eIF4E assembly lacks ontogenic modifications and may be associated with resistance to insulin stimulation in older animals. Because whole body protein turnover is higher in neonates compared with adults, further studies are required to examine changes in the protein degradation process in muscle during sepsis in neonatal and mature animals.

Acknowledgments. The authors thank Jerome Stubblefield for assistance with care of animals, Jillian Fleming and Rose Almonaci for laboratory support, and Linda Weiser for secretarial assistance.

\section{REFERENCES}

1. Levy MM, Fink MP, Marshall JC, Abraham E, Angus D, Cook D, Cohen J, Opal SM, Vincent JL, Ramsay G 20032001 SCCM/ESICM/ACCP/ATS/SIS International Sepsis Definitions conference. Crit Care Med 31:1250-1256

2. Goldstein B, Giroir B, Randolph A 2005 International pediatric sepsis consensus conference: definitions for sepsis and organ dysfunction in pediatrics. Pediatr Crit Care Med 6:2-8

3. Watson RS, Carcillo JA, Linde-Zwirble WT, Clermont G, Lidicker J, Angus DC 2003 The epidemiology of severe sepsis in children in the United States. Am J Respir Crit Care Med 167:695-701 
4. Lang $\mathrm{CH}$, Frost RA, Vary TC 2007 Regulation of muscle protein synthesis during sepsis and inflammation. Am J Physiol Endocrinol Metab 293:E453-E459

5. Smith IJ, Lecker SH, Hasselgren PO 2008 Calpain activity and muscle wasting in sepsis. Am J Physiol Endocrinol Metab 295:E762-E771

6. Bruins MJ, Deutz NE, Soeters PB 2003 Aspects of organ protein, amino acid and glucose metabolism in a porcine model of hypermetabolic sepsis. Clin Sci (Lond) 104:127-141

7. Winkelman C 2004 Inactivity and inflammation: selected cytokines as biologic mediators in muscle dysfunction during critical illness. AACN Clin Issues 15:74-82

8. Kimball SR, Orellana RA, O'Connor PM, Suryawan A, Bush JA, Nguyen HV, Thivierge MC, Jefferson LS, Davis TA 2003 Endotoxin induces differential regulation of mTOR-dependent signaling in skeletal muscle and liver of neonatal pigs. Am J Physiol Endocrinol Metab 285:E637-E644

9. Orellana RA, O'Connor PM, Nguyen HV, Bush JA, Suryawan A, Thivierge MC Fiorotto ML, Davis TA 2002 Endotoxemia reduces skeletal muscle protein synthesis in neonates. Am J Physiol Endocrinol Metab 283:E909-E916

10. Davis TA, Fiorotto ML, Burrin DG, Reeds PJ, Nguyen HV, Beckett PR, Vann RC, O'Connor PM 2002 Stimulation of protein synthesis by both insulin and amino acids is unique to skeletal muscle in neonatal pigs. Am J Physiol Endocrinol Metab 282:E880-E890

11. Kimball SR, Jefferson LS, Nguyen HV, Suryawan A, Bush JA, Davis TA 2000 Feeding stimulates protein synthesis in muscle and liver of neonatal pigs through an mTOR-dependent process. Am J Physiol Endocrinol Metab 279:E1080-E1087

12. Suryawan A, Nguyen HV, Bush JA, Davis TA 2001 Developmental changes in the feeding-induced activation of the insulin-signaling pathway in neonatal pigs. Am J Physiol Endocrinol Metab 281:E908-E915

13. Suryawan A, Jeyapalan AS, Orellana RA, Wilson FA, Nguyen HV, Davis TA 2008 Leucine stimulates protein synthesis in skeletal muscle of neonatal pigs by enhancing mTORC1 activation. Am J Physiol Endocrinol Metab 295:E868-E875

14. Hasselgren PO, Fischer JE 1998 Sepsis: stimulation of energy-dependent protein breakdown resulting in protein loss in skeletal muscle. World J Surg 22:203-208

15. Vary TC, Lynch CJ 2007 Nutrient signaling components controlling protein synthesis in striated muscle. J Nutr 137:1835-1843

16. Ruvinsky I, Meyuhas O 2006 Ribosomal protein S6 phosphorylation: from protein synthesis to cell size. Trends Biochem Sci 31:342-348

17. Crozier SJ, Vary TC, Kimball SR, Jefferson LS 2005 Cellular energy status modulates translational control mechanisms in ischemic-reperfused rat hearts. Am J Physiol Heart Circ Physiol 289:H1242-H1250

18. Davis TA, Fiorotto ML, Nguyen HV, Burrin DG 1999 Aminoacyl-tRNA and tissue free amino acid pools are equilibrated after a flooding dose of phenylalanine. Am J Physiol 277:E103-E109

19. Orellana RA, Jeyapalan A, Escobar J, Frank JW, Nguyen HV, Suryawan A, Davis TA 2007 Amino acids augment muscle protein synthesis in neonatal pigs during acute endotoxemia by stimulating mTOR-dependent translation initiation. Am J Physiol Endocrinol Metab 293:E1416-E1425
20. Suryawan A, Escobar J, Frank JW, Nguyen HV, Davis TA 2006 Developmental regulation of the activation of signaling components leading to translation initiation in skeletal muscle of neonatal pigs. Am J Physiol Endocrinol Metab 291:E849-E859

21. Davis TA, Fiorotto ML 2009 Regulation of muscle growth in neonates. Curr Opin Clin Nutr Metab Care 12:78-85

22. Davis TA, Nguyen HV, Suryawan A, Bush JA, Jefferson LS, Kimball SR 2000 Developmental changes in the feeding-induced stimulation of translation initiation in muscle of neonatal pigs. Am J Physiol Endocrinol Metab 279:E1226-E1234

23. Drummond MJ, Dreyer HC, Pennings B, Fry CS, Dhanani S, Dillon EL, SheffieldMoore M, Volpi E, Rasmussen BB 2008 Skeletal muscle protein anabolic response to resistance exercise and essential amino acids is delayed with aging. J Appl Physiol 104:1452-1461

24. Orellana RA, O'Connor PM, Bush JA, Suryawan A, Thivierge MC, Nguyen HV, Fiorotto ML, Davis TA 2006 Modulation of muscle protein synthesis by insulin is maintained during neonatal endotoxemia. Am J Physiol Endocrinol Metab 291:E159-E166

25. Zeller WP, Goto M, Witek-Janusek L, Hurley RM 1991 Mortality, temporal substrate and insulin responses to endotoxic shock in zero, ten and twenty-eight day old rats. Surg Gynecol Obstet 173:375-383

26. Lang CH 2001 Sepsis-induced changes in pancreatic hormone secretion. In: Jefferson LS, Cherrington AD (eds) Handbook of Physiology. Oxford University Press, Oxford, pp 999-1013

27. Davis TA, Burrin DG, Fiorotto ML, Nguyen HV 1996 Protein synthesis in skeletal muscle and jejunum is more responsive to feeding in 7-than in 26-day-old pigs. Am J Physiol 270:E802-E809

28. Davis TA, Suryawan A, Orellana RA, Nguyen HV, Fiorotto ML 2008 Postnatal ontogeny of skeletal muscle protein synthesis in pigs. J Anim Sci 86:E13-E18

29. Jurasinski C, Gray K, Vary TC 1995 Modulation of skeletal muscle protein synthesis by amino acids and insulin during sepsis. Metabolism 44:1130-1138

30. Mizock BA 2000 Metabolic derangements in sepsis and septic shock. Crit Care Clin 16:319-336 vii

31. Vary TC, Jefferson LS, Kimball SR 2001 Insulin fails to stimulate muscle protein synthesis in sepsis despite unimpaired signaling to 4E-BP1 and S6K1. Am J Physiol Endocrinol Metab 281:E1045-E1053

32. Clemens MJ 2005 Translational control in virus-infected cells: models for cellular stress responses. Semin Cell Dev Biol 16:13-20

33. Constantinou C, Bushell M, Jeffrey IW, Tilleray V, West M, Frost V, Hensold J, Clemens MJ 2003 p53-induced inhibition of protein synthesis is independent of apoptosis. Eur J Biochem 270:3122-3132

34. Orellana RA, Kimball SR, Suryawan A, Escobar J, Nguyen HV, Jefferson LS, Davis TA 2007 Insulin stimulates muscle protein synthesis in neonates during endotoxemia despite repression of translation initiation. Am J Physiol Endocrinol Metab 292:E629-E636 